\title{
Heart Failure as First Sign of Development of Cardiac Metastases in a Patient with Diagnosis of Papillary Thyroid Carcinoma on Treatment with Tyrosine-Kinase Inhibitors: Differential Diagnoses and Clinical Management
}

\author{
Gema Bruixola $^{a} \quad$ Ángel Segura ${ }^{a}$ Javier Caballero ${ }^{a} \quad$ Ana Andrés $^{b}$ \\ Encarnación Reche ${ }^{a}$ Corina Escoín ${ }^{a}$ Roberto Díaz-Beveridge ${ }^{a}$ \\ ${ }^{\mathrm{a}}$ Medical Oncology Department and ${ }^{\mathrm{b}}$ Cardiology Department, La Fe University and \\ Polytechnic Hospital, Valencia, Spain
}

\section{Key Words}

Thyroid cancer - Cardiac metastases - Sorafenib - Sunitinib · Tyrosine-kinase inhibitors .

Cardiac magnetic resonance

\begin{abstract}
Background: Cardiac metastases from papillary thyroid carcinoma are very uncommon. Their incidence is rising due to improvements in survival and diagnosis; nevertheless, our patient is the fourth case reported up to date. There are no clinical trials available in this scenario. Therefore, treatment choice is made based on clinical experience and case reports; notably, the largest case report series was prior to the approval for using tyrosine-kinase inhibitors in thyroid cancer. Patient: A 73-year-old lady had dedifferentiated papillary thyroid cancer with ongoing sorafenib. After 9 months on this treatment, she presented with dyspnea and heart failure. Differential diagnosis included infection, progression of disease and cardiotoxicity. After a comprehensive assessment (echocardiography, computed tomography, PET, magnetic resonance), we found progression of lung disease, and the appearance of heart metastases. Results: After recovering from the basal status, she started on second-line treatment with sunitinib, which was well-tolerated. She achieved stable disease with a
\end{abstract}


Bruixola et al.: Heart Failure as First Sign of Development of Cardiac Metastases in a Patient with Diagnosis of Papillary Thyroid Carcinoma on Treatment with TyrosineKinase Inhibitors: Differential Diagnoses and Clinical Management

decrease in tumor marker levels. Conclusions: We should include cardiac metastases in the differential diagnosis of heart failure in cancer patients. Magnetic resonance imaging is the gold standard for assessment. Sorafenib is the mainstay of the first-line therapy in metastatic thyroid cancer, achieving long-term disease control with good tolerance. Sunitinib could be a safe second-line treatment option (not cardiotoxicity related) with promising results. Therefore, our report presents a sequence of treatment with tyrosine-kinase inhibitors in metastatic thyroid carcinoma with an encouraging outcome, which deserves further investigation.

(c) 2014 S. Karger AG, Basel

\section{Introduction}

Cardiac metastases from thyroid cancer are a rare entity; in fact, its frequency reported in historical series ranges from 0 to $2 \%$ [1]. The improvements in survival of thyroid cancer patients and current advances in imaging diagnoses have contributed to increase its incidence [2].

Nevertheless, after a comprehensive literature review, we found only 15 case reports in the last 35 years $[3,4]$. Thyroid cancer histologic subtypes more prone to develop cardiac metastases are anaplastic thyroid cancer, follicular thyroid cancer, and Hürthle cell cancer. To date, there are only 3 case reports of cardiac metastases from papillary thyroid carcinoma, so our patient will be the fourth case.

\section{Case Report}

A 73-year-old lady with a personal history of well-controlled high blood pressure and chronic atrial fibrillation on anticoagulant therapy, but with performance status 0 presented with a neck enlargement mass in May 2010. She underwent a total thyroidectomy and therapeutic lymph node neck dissection achieving a complete resection in June 2010. The initial diagnosis was a papillary thyroid carcinoma measuring $5.5 \times 4 \times 4 \mathrm{~cm}$, with regional lymph node involvement (1/4; pathologic stage, pT4N1aM0). No residual uptake was seen in the post-therapeutic radioiodine-131 whole-body scan. Complementary treatment was not prescribed.

Three months after the first operation, the patient presented with a tender lump in the left supraclavicular fossa. Imaging studies confirmed this sole recurrence site. The lymph node was excised and the histopathology analysis showed features consistent with dedifferentiated papillary thyroid cancer with a solid, insular and trabecular growth pattern, frequent mitosis and pleomorphic nuclei. Immunohistochemical examination demonstrated that the cells stained positively for thyroglobulin, thyroid transcription factor (TTF1), bcl2, e-cadherin, cyclin D1, CD15 and Ki-67 (10\% ratio) and were negative for calcitonin and HBM45. Postoperative treatment with radioactive iodine-131 (I-131) at a dose of $150 \mathrm{mCi}$ was advised. After a disease-free interval of 18 months, in May 2011, she had a new relapse in form of isolated cervical lymph node metastases, with a negative $18 \mathrm{~F}$-fluorodeoxyglucosepositron emission tomography elsewhere. A new operation was performed to remove the lesion. Again, the pathology showed this to be a relapse of her poorly differentiated thyroid carcinoma (PDTC), with papillary features. She completed adjuvant treatment with external beam radiotherapy over the neck and mediastinum ( $60 \mathrm{~Gy}$ for 30 fractions). Unfortunately, a year later, in May 2012, in a follow-up visit, thyroglobulin level rose to 3,042 ng/ml; an I-131 scan and a positron emission tomography and computed tomography (PET/CT) were 
Bruixola et al.: Heart Failure as First Sign of Development of Cardiac Metastases in a Patient with Diagnosis of Papillary Thyroid Carcinoma on Treatment with TyrosineKinase Inhibitors: Differential Diagnoses and Clinical Management

requested; metabolically active paratracheal lymph nodes and new lung metastases were observed. I-131 rechallenge was indicated at a dose of $178 \mathrm{mCi}$. A partial response and a decrease in thyroglobulin levels $(2,580 \mathrm{ng} / \mathrm{ml})$ were obtained. In March 2013, thyroglobulin level reached 9,946 ng/ml and a new PET/CT scan demonstrated progression of her pulmonary and ganglionic disease. At this point, treatment with sorafenib $400 \mathrm{mg}$ orally twice daily was initiated. Her disease remained stable for 8 months (thyroglobulin level: $8,298 \mathrm{ng} / \mathrm{ml}$ ) and the patient did not experience significant side effects (except grade 1 mucositis and hand-foot syndrome).

In October 2013, the patient came to the emergency department at this hospital because of progressive dyspnea, irritative cough, pleuritic chest pain, orthopnea and oliguria. On examination, the temperature was $37^{\circ} \mathrm{C}$, the blood pressure $110 / 80 \mathrm{~mm} \mathrm{Hg}$, the pulse 90 beats per minute, the respiratory rate 22 breaths per minute and the oxygen saturation $90 \%$ while the patient was breathing ambient air. There were decreased lung sounds with expiratory wheezes bilaterally and crackles at the right base and there was 2+ edema of the legs. Hemogram and biochemistry showed mild anemia (hemoglobin $11 \mathrm{~g} / \mathrm{dl}$ ) without any other abnormalities. Chest radiography showed a sclerotic lesion in the sixth dorsal vertebra, alveolar diffuse infiltrate in the right lung base, right paratracheal lymph node enlargement, and cardiomegaly. Electrocardiogram (ECG) was reportedly normal with no changes compared with the previous one.

She was admitted to the hospital with depletive treatment, empirical antibiotics, and steroids, according to the initial diagnosis of acute heart failure, in the context of a likely respiratory infection. Symptoms were stabilized and the patient reported clinical improvement; however, progression of disease could not be ruled out, so a diagnostic procedure was performed.

Transthoracic echocardiography revealed minimal mitral and tricuspid regurgitation with an estimated left ventricular ejection fraction of $60 \%$. A moderate circumferential pericardial effusion was present without evidence of tamponade; echodensities along the visceral pericardium were considered to be consistent with the deposition of fibrin or metastases. A nodular mass in the right atrium suspicious of metastases was observed as well.

The assessment was completed with a PET/CT scan and cardiac magnetic resonance imaging (MRI) which demonstrated further significant progression in the lungs and confirmed the development of bone and cardiac metastases in the pericardium and the right atrium (fig. 1). At this time, the thyroglobulin levels reached their maximum $(28,818 \mathrm{ng} / \mathrm{ml}$; fig. 2).

Due to the evolution after the discharge, and the lack of relevant toxicity at any time during the previous treatment with sorafenib, the patient was very keen on having further treatment.

Concern regarding morbidity and efficacy of this approach was raised, and sunitinib at a dose of $37.5 \mathrm{mg} /$ day, daily, was initiated in November 2013, with the approval of the Committee for High Impact Drugs. Again, therapy was well tolerated with easily manageable adverse effects; the patient experienced only grade 1 high blood pressure and fatigue. At the time of the last follow-up after 4 months of treatment, the patient's tumor was stable with respect to size in the imaging assessment; however, it demonstrated a marked reduction in thyroglobulin level $(8,625 \mathrm{ng} / \mathrm{ml})$, and the patient likewise was experiencing continued improvement of her symptoms and a benefit to her quality of life, although one dose reduction was required. Unfortunately, 1 month later her general condition started to deteriorate due to new exacerbation of heart failure; then, palliative treatment for symptom 
Bruixola et al.: Heart Failure as First Sign of Development of Cardiac Metastases in a Patient with Diagnosis of Papillary Thyroid Carcinoma on Treatment with TyrosineKinase Inhibitors: Differential Diagnoses and Clinical Management

control was decided, with home care support. Finally she died in April 2014 due to cardiac congestive failure.

\section{Discussion}

Cardiac metastases have historically been considered an exceptional event, occurring less than $2 \%$ of the time [1]. The three main reasons could be: First, cancers whose route of spread could involve the heart are very scarce. Second, the majority of cardiac metastases have indolent behavior or unspecific symptoms that could be attributed to other causes [5], so its diagnosis has been challenging. Third, the availability and accuracy of imaging-based diagnostic systems used to be low compared to today. Owing to the facts mentioned above, most of the final diagnoses were performed by autopsies.

However, both improvement in cancer treatment with an increased longevity of cancer patients and the development of diagnosis techniques, like cardiac MRI, have contributed to the current incidence of cardiac metastases which has increased to slightly above $10 \%$ [5].

We can distinguish three groups among cardiac metastases according to its primary tumor origin: uncommon primary tumors that have a high rate of metastasis to the heart (malignant melanoma, malignant germ cell neoplasm, malignant thymoma); common tumors that have an intermediate rate of cardiac metastases but account for the greatest number of cardiac metastasis (carcinoma of the stomach, liver, ovary, colon, and rectum), and common tumors with rare metastases to the heart. Our case could be classified in this last category [5].

The incidence and prevalence of thyroid cancer is rising; actually, it has become the ninth cancer in frequency in the developed countries [6]. Over $90 \%$ of cases are welldifferentiated thyroid cancers (WDTCs), originated from the follicular cells, encompassing papillary and follicular thyroid forms (PTCs and FTCs).

The PTC is considered to be potentially curable by using a multimodal treatment, which combines surgery, radioactive iodine, and TSH-suppressive hormonal therapy. Nevertheless, $30 \%$ of PTCs have a relapse, and the recurrence can be associated to a cell dedifferentiation. It implies a more aggressive biological behavior, characterized by a fast growth and metastatization, loss of the iodine uptake and radiotherapy resistance.

This situation was observed in our patient, who presented an early nodal recurrence, resectable, whose pathological report was confirmed as PDTC, with papillary features. PDTC is a well-defined diagnosis entity since the Turin experts meeting in 2006, with features and prognosis in between WDTC and anaplastic thyroid carcinomas [7]. Figure 3 outlines how PDTC can arise 'de novo', or like in our patient, can be developed from WDTC with the appearance of new genetic alterations, such as point mutations and translocations that increase mitogenesis and cell proliferation.

The carcinogenesis in thyroid carcinomas is preceded by unopposed activation of either the mitogen-activated protein kinase pathway (controlled by the genes RET, RAS BRAF) or the phosphatidylinositol-3-kinase pathway [8].

PDTC presents several of these genetic alterations: RAS mutations have been observed in $30-35 \%$ and BRAF mutations have been found in $45 \%$. Interestingly, these 2 mutations are mutually exclusive. TP53 mutations in a range of $20-30 \%$ and overexpression of tyrosine-kinase receptors, including epidermal growth factor receptor and vascularendothelial growth factor receptor (VEGFR) have been reported as well [8]. Table 1 illustrates the prevalence of genetic alterations in regard to the different histological subtypes of thyroid cancer. 
Bruixola et al.: Heart Failure as First Sign of Development of Cardiac Metastases in a Patient with Diagnosis of Papillary Thyroid Carcinoma on Treatment with TyrosineKinase Inhibitors: Differential Diagnoses and Clinical Management

This knowledge has imposed a significant change in the management of this disease. The current approach is to emphasize the use of new targeted therapies against these potential targets; so, it supports the use of multikinase tyrosine-kinase inhibitors (such as sorafenib, sunitinib, vandetanib), drugs which may act by blocking several targets (VEGFR, RET, BRAF) instead of classic cytotoxic agents.

The efficacy and safety of sorafenib, the first-line treatment for metastatic disease used in our patient, have been proved in three phase II trials [9]. It has recently been approved by the US Food and Drug Administration in October 2013 on the basis of the results of a phase III double-blind, randomized, controlled trial, with 417 advanced thyroid cancer patients with iodine-refractory disease. It demonstrated that patients on sorafenib obtained a benefit in median disease-free survival (10.58 vs. 5.8 months) and improvement in overall response rate (12 vs. $1 \%$ ), with good toxicity profile (hand-foot syndrome and diarrhea) [10]. Considering all of the above, sorafenib should be the mainstay first-line treatment in metastatic thyroid carcinoma, due to its good results in efficacy and toxicity. Our patient presented with stable disease and excellent tolerance during the whole 9 months of treatment, which is consistent with the published data; notably, our patient's baseline characteristics were worse than the patients enrolled in the study; in spite of that, improved clinical outcome persisted.

Then, she needed to be hospitalized due to worsening dyspnea in the context of the first episode of congestive heart failure.

Although the chief symptom of dyspnea led us to think first of pulmonary disease, like concomitant respiratory infection which could trigger the congestive heart failure episode, the additional history of our patient demanded consideration of causes of dyspnea that are more likely in a patient with aggressive PDTC treated with radiotherapy and systemic treatment with tyrosine-kinase inhibitors. Therefore, conditions like cardiotoxicity from sorafenib (table 2) [11], radiation-related complications (pneumonitis or radiationassociated constrictive pericarditis), progression of disease (involving either lungs, heart or both), and malignant pericardial effusion should be ruled out.

Radiation-related complications were unlikely, and neither the chronology (pneumonitis usually appears 3-12 weeks after the ending of treatment) nor the radiological findings were consistent with them.

Cardiotoxicity was ruled out with the preliminary results (ECG without abnormalities and echocardiography with conserved left ventricular ejection fraction) as well. Furthermore, the final diagnosis was suggested with some suspicious findings in the initial echocardiography, which were suggesting the existence of metastases in the pericardium and the right atrium, but inconclusive to state it.

To achieve the diagnosis confirmation, we requested a cardiac MRI, which is considered as 'gold standard' for morphological assessment of the heart. We completed the diagnosis procedure with a PET/CT scan, the optimal imaging technique to evaluate undifferentiated thyroid cancer with loss of radioiodine uptake ability. The MRI showed two new sites of disease in the pericardium and the right atrium which were associated with abnormal metabolic activity in the PET/CT. In addition, the PET/CT showed further progression of the disease with new hypermetabolic foci in the lungs and in the thoracic vertebras.

In the last comprehensive literature review published in 2011 that covers the last 130 years [15], 54 patients with cardiac metastases from thyroid cancer were identified, all with poor outcome (survival since cardiac metastasis presentation $<5$ months).

Elective treatment for cardiac metastases is a radical surgery [12], but this is only possible in very selected patients. Favourable outcomes have also been reported by using radiotherapy, as in cardiac sarcomas. 
The main goal in the majority of cardiac metastasis case reports published to date was to control cardiologic symptoms because of its life-threatening condition and its complex management. Contrary to the facts mentioned above, our patient experienced cardiologic clinical improvement just with medical treatment adjustment. Therefore, due to the new symptomatic systemic progression, without requiring locoregional control maneuver, systemic second-line therapeutic options were considered for our patient.

Sunitinib, an anti-VEGFR, platelet-derived growth factor receptor, multikinase drug, has shown successful results in three phase II trials for iodine-refractory thyroid carcinoma in second-line treatment [13-15], achieving partial responses or stabilization of disease, without relevant side effects.

Owing to its proved activity and its low cardiotoxicity rate [14], finally we decided to start sunitinib; a stabilization of the disease with a lack of relevant toxicity was observed in our case after 4 months of treatment.

Therefore, our case report presents a sequence of treatment with tyrosine-kinase inhibitors in metastatic thyroid carcinoma with an encouraging outcome; we achieved long-term disease stabilization (over 13 months) with clinical benefit and good toxicity profile, without increasing cardiotoxicity, in spite of the development of heart metastases.

There is a need to confirm our experience in prospective studies; further investigations to establish the optimal sequence therapy in this setting are required.

\section{Disclosure Statement}

The authors have no conflicts of interest to declare.

\section{References}

1 Abraham KP, Reddy V, Gattuso P: Neoplasms metastatic to the heart: review of 3314 consecutive autopsies. Am J Cardiovasc Pathol 1990;3:195-198.

-2 Dasgupta T, Barani IJ, Roach M 3rd: Successful radiation treatment of anaplastic thyroid carcinoma metastatic to the right cardiac atrium and ventricle in a pacemaker-dependent patient. Radiat Oncol $2011 ; 6: 16$

-3 Fukuda A, Saito T, Imai M, Ishii K, Miwa K: Metastatic cardiac papillary carcinoma originating from the thyroid in both ventricles with a mobile right ventricular pendunculated tumor. Jpn Circ J 2000;64:890-892.

4 Giuffrida D, Gharib H: Cardiac metastasis from primary anaplastic thyroid carcinoma: report of three cases and a review of the literature. Endocr Relat Cancer 2001;8:71-73.

5 Butany J, Nair V, Nasemuddin A, Nair GM, Catton A, Yau T: Cardiac tumours: diagnosis and management. Lancet Oncol 2005;6:219-228.

6 Howlader N, Noone AM, Krapcho M, Garshell J, Neyman N, Altekruse SF, Kosary CL, Yu M, Ruhl J, Tatalovich Z, Cho H, Mariotto A, Lewis DR, Chen HS, Feuer EJ, Cronin KA (eds): SEER Cancer Statistics Review, 19752010, National Cancer Institute. Bethesda, Md., http://seer.cancer.gov/csr/1975_2010/, based on November 2012 SEER data submission, posted to the SEER web site, April 2013.

7 Volante M, Collini P, Nikiforv YE, et al: Poorly differentiated thyroid carcinoma: the Turin proposal for the use of uniform diagnostic criteria and an algorithmic diagnostic approach. Am J Surg Pathol 2007;31:12561264.

-8 Hannallah J, Rose J, Guerrero MA: Comprehensive literature review: recent advances in diagnosing and managing patients with poorly differentiated thyroid carcinoma. Int J Endocrinol 2013;2013:317487.

9 Keefe S, Troxel A, Rhee S, et al: Phase II trial of sorafenib in patients with advanced thyroid cancer. J Clin Oncol 2011;29:abstr 5562.

10 Brose M, Nutting C, Jarzab B, et al: Sorafenib in locally advanced or metastatic patients with radioactive iodine-refractory differentiated thyroid cancer: the phase III DECISION trial. J Clin Oncol 2013;31:abstr 4.

$\checkmark 11$ Mellor HR, Bell AR, Valentin JP, Roberst RR: Cardiotoxicity associated with targeting kinase-pathways in cancer. Toxicol Sci 2011;120:14-32.

12 Catford SR, Lee KT, Pace MD, Marasco SF, Longano A, Topliss DJ: Cardiac metastasis from thyroid carcinoma. Thyroid 2011;8:855-866. 


\section{Case Reports in Oncology}

\begin{tabular}{l|l}
\hline Case Rep Oncol 2014;7:591-599 \\
\hline DOI: $10.1159 / 000366192$ & $\begin{array}{l}\text { C 2014 S. Karger AG, Basel } \\
\text { www.karger.com/cro }\end{array}$ \\
\hline
\end{tabular}

Bruixola et al.: Heart Failure as First Sign of Development of Cardiac Metastases in a Patient with Diagnosis of Papillary Thyroid Carcinoma on Treatment with TyrosineKinase Inhibitors: Differential Diagnoses and Clinical Management

13 Carr LL, Mankoff DA, Goulart BH, et al: Phase II study of daily sunitinib in FDG-PET-positive, iodinerefractory differentiated thyroid cancer and metastatic medullary carcinoma of the thyroid with functional imaging correlation. Clin Cancer Res 2010;16:5260-5268.

14 Cohen EE, Needles BM, Cullen KJ, et al: Phase 2 study of sunitinib in refractory thyroid cancer (abstract). J Clin Oncol 2008;26:suppl. Abstract no. 6025. Presented at the Annual Meeting of the American Society of Clinical Oncology (ASCO); May 30-June 3, 2008; Chicago, Ill., USA.

15 De Souza JA, Busaidy N, Zimrin A, et al: Phase II trial of sunitinib in medullary thyroid cancer (MTC) (abstract). J Clin Oncol 2010;28:15s. Abstract no. 5504. Presented at the Annual Meeting of the American Society of Clinical Oncology (ASCO); June 4-8, 2010; Chicago, Ill., USA.

-16 Escudier B, Eisen T, Stadler WM, et al: Sorafenib for treatment of renal cell carcinoma: final efficacy and safety results of the phase III treatment approaches in renal cancer global evaluation trial. J Clin Oncol 2009;27:3312-3318.

17 Schmidinger M, Zielinski CC, Vogl UM, et al: Cardiac toxicity of sunitinib and sorafenib in patients with metastatic renal cell carcinoma. J Clin Oncol 2008;26:5204-5212.

18 Veronese ML, Mosenkis A, Flaherty KT, et al: Mechanisms of hypertension associated with BAY 43-9006. J Clin Oncol 2006;24:1363-1369.

19 Haznedar J0, Patyna S, Bello CL, et al: Single- and multiple-dose disposition kinetics of sunitinib malate, a multitargeted receptor tyrosine kinase inhibitor: comparative plasma kinetics in non-clinical species. Cancer Chemother Pharmacol 2009;64:691-706.

20 Kerkela R, Woulfe KC, Durand JB, et al: Sunitinib-induced cardiotoxicity is mediated by off-target inhibition of AMP-activated protein kinase. Clin Transl Sci 2009;2:15-25.

21 Faivre S, Delbaldo C, Vera K, et al: Safety, pharmacokinetic, and antitumor activity of SU11248, a novel oral multitarget tyrosine kinase inhibitor, in patients with cancer. J Clin Oncol 2006;24:25-35.

22 Deprimo SE, Bello CL, Smeraglia J, et al: Circulating protein biomarkers of pharmacodynamic activity of sunitinib in patients with metastatic renal cell carcinoma: modulation of VEGF and VEGF-related proteins. J Transl Med 2007;5:32.

Table 1. Prevalence of genetic alterations according to the histological subtype of thyroid cancer

\begin{tabular}{lcclc}
\hline $\begin{array}{l}\text { Altered } \\
\text { gene }\end{array}$ & $\begin{array}{l}\text { Papillary } \\
\text { thyroid } \\
\text { carcinoma }\end{array}$ & $\begin{array}{l}\text { Follicular } \\
\text { thyroid } \\
\text { carcinoma }\end{array}$ & $\begin{array}{l}\text { Poorly differen- } \\
\text { tiated thyroid } \\
\text { carcinoma }\end{array}$ & $\begin{array}{l}\text { Anaplastic } \\
\text { thyroid } \\
\text { carcinoma }\end{array}$ \\
\hline RET/PTC & $20 \%$ & 0 & 0 & 0 \\
TP53 & 0 & 0 & $20-30 \%$ & $65-70 \%$ \\
BRAF & $45 \%$ & 0 & $15 \%$ & $20-25 \%$ \\
RAS & $10-15 \%$ & $45 \%$ & $30-35 \%$ & $50-55 \%$ \\
$\beta$-Catenin & 0 & 0 & $20-25 \%$ & $65 \%$ \\
PAX8:PPAR & 0 & $35 \%$ & 0 & 0 \\
\hline
\end{tabular}




\section{Case Reports in Oncology}

\begin{tabular}{l|l}
\hline Case Rep Oncol 2014;7:591-599 \\
\hline DOI: $10.1159 / 000366192$ & $\begin{array}{l}\text { C 2014 S. Karger AG, Basel } \\
\text { www.karger.com/cro }\end{array}$ \\
\hline
\end{tabular}

Bruixola et al.: Heart Failure as First Sign of Development of Cardiac Metastases in a Patient with Diagnosis of Papillary Thyroid Carcinoma on Treatment with TyrosineKinase Inhibitors: Differential Diagnoses and Clinical Management

Table 2. Cardiotoxicity related with tyrosine-kinase inhibitors

\begin{tabular}{|c|c|c|c|c|}
\hline Drug & Target & Indications & Clinical findings & References \\
\hline Sorafenib & $\begin{array}{l}\text { Raf-1, b-Raf, } \\
\text { VEGFR1, 2, 3, } \\
\text { PDGFR, c-KIT }\end{array}$ & $\begin{array}{l}\text { HCC, RCC, } \\
\text { thyroid cancer }\end{array}$ & $\begin{array}{l}\text { ischemic infarction, } \\
\text { ECG abnormalities, } \\
\text { high blood pressure }\end{array}$ & $\begin{array}{l}\text { Escudier et al. [16], 2009; } \\
\text { Schmidinger et al. [17], 2008; } \\
\text { Veronese et al. [18], } 2006\end{array}$ \\
\hline Sunitinib & $\begin{array}{l}\text { VEGFR1, } 3 \text {, } \\
\text { PDGFR, RET, } \\
\text { c-kit, FLT3 }\end{array}$ & RCC, GIST & $\begin{array}{l}\text { long QT syndrome, } \\
\text { FEVI reduced, } \\
\text { heart failure }\end{array}$ & $\begin{array}{l}\text { Haznedar et al. [19], 2009; } \\
\text { Kerkela et al. [20], 2009; } \\
\text { Faivre et al. [21], 2006; } \\
\text { Deprimo et al. [22], 2007 }\end{array}$ \\
\hline
\end{tabular}

PDGFR = Platelet-derived growth factor receptor; HCC = hepatocarcinoma; RCC = renal cell carcinoma; GIST = gastrointestinal stroma tumor; FEVI = ventricular ejection fraction.

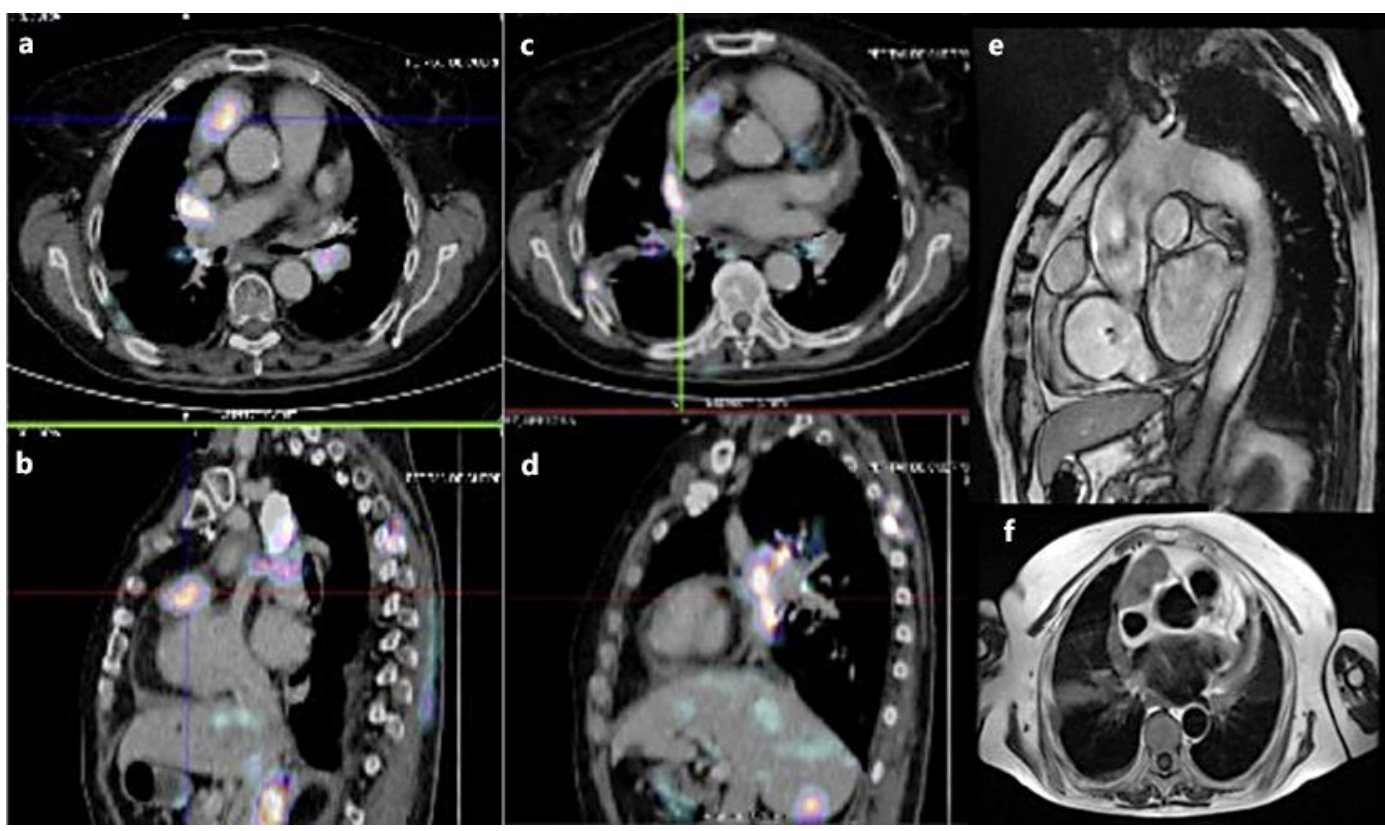

Fig. 1. Imaging, October 2013. a, b PET/CT scan axial and coronal images demonstrate abnormal metabolic activity corresponding to right atrium metastases. c, d PET scan axial and coronal images show hypermetabolic foci in pericardium, consistent with pericardium metastases. e, f Cardiac MRI T1 and FLAIR demonstrating pericardium enhancement. 
Bruixola et al.: Heart Failure as First Sign of Development of Cardiac Metastases in a Patient with Diagnosis of Papillary Thyroid Carcinoma on Treatment with TyrosineKinase Inhibitors: Differential Diagnoses and Clinical Management

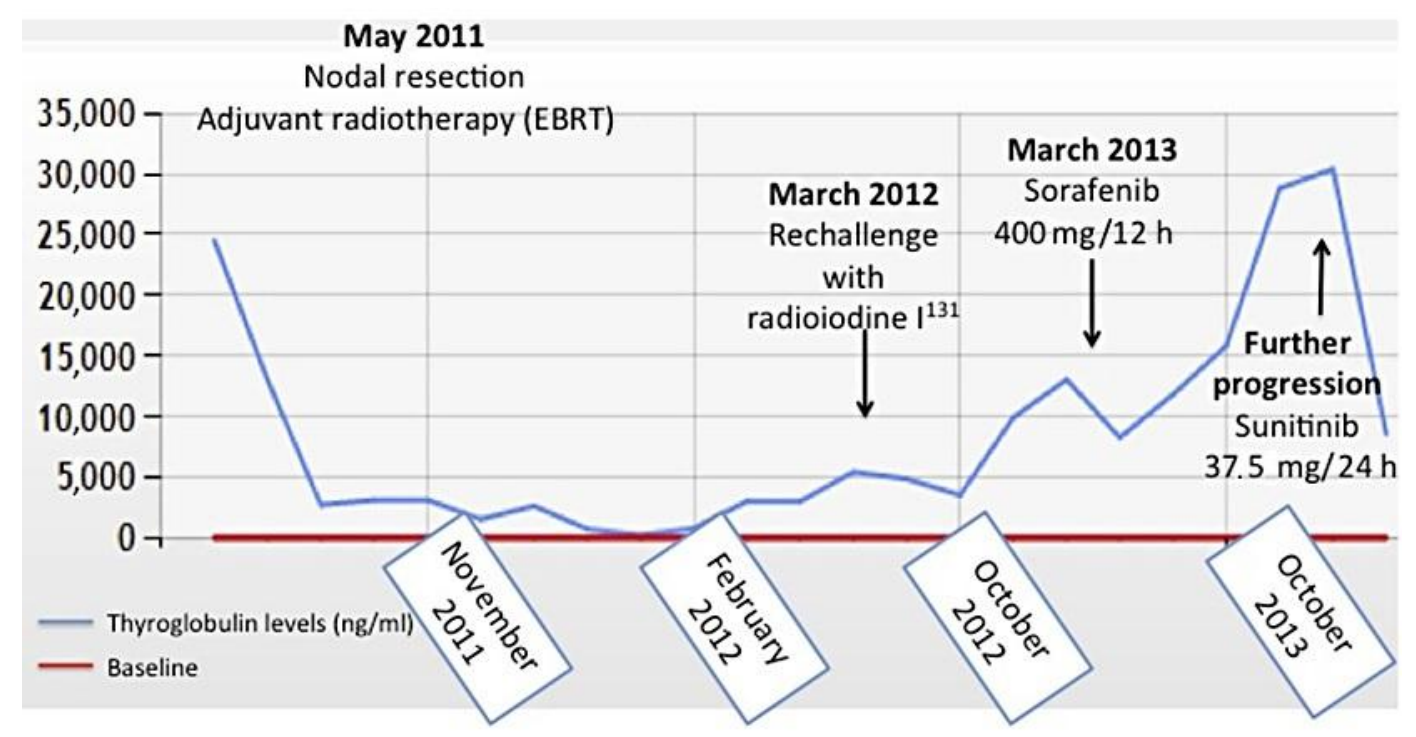

Fig. 2. Evolution of thyroglobulin levels with the treatment. EBRT = External beam radiotherapy.

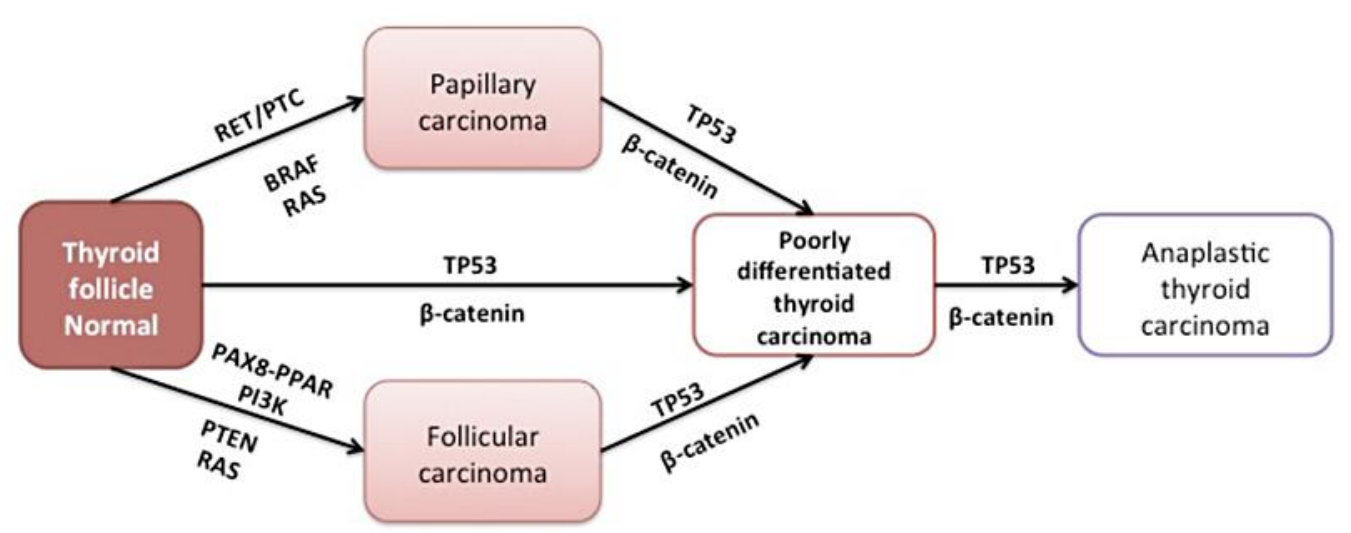

Fig. 3. Genetic alterations in PDTC. PDTC can arise 'de novo' or develop from WDTC. Adapted from [8]. 